DOI: http://dx.doi.org/10.22484/2177-5788.2017v43n2p277-294

\title{
As novas diretrizes curriculares para os cursos de jornalismo e o possível fortalecimento da ética profissional ${ }^{1}$
}

\author{
Lilian Saback de Sá Moraes
}

Resumo: O objetivo deste artigo é contribuir para o debate em torno da ética como prioridade na prática jornalística e o papel da universidade na formação profissional. $O$ texto apresenta os primeiros resultados da pesquisa: As PUCs e as novas diretrizes para o curso de jornalismo: questões de ética e cidadania por um mundo sustentável, e fundamenta-se teoricamente a partir de textos acadêmicos sobre ética e ensino de jornalismo, e com os depoimentos de Muniz Sodré, professor emérito da UFRJ e Miguel Pereira, coordenador do Projeto Comunicar/PUC-Rio. O estudo traz, ainda, as principais informações obtidas por meio de dinâmicas realizadas com grupos de alunos da disciplina de ética dos cursos de jornalismo das PUCs de Minas Gerais e Goiânia. Com o método que une a teoria a escuta e aplicação da prática, a autora sustenta a necessidade de investir na formação acadêmica do jornalista, com o resgate da ética como essência fundamental para o jornalismo.

Palavras-chave: Jornalismo. Ensino de jornalismo. Ética. Diretrizes curriculares. PUC.

\section{The new curricular guidelines for journalism courses and the possible strengthening of professional ethics}

Abstract: The aim of this article is to contribute to the debate about ethics as a priority in journalistic practice and the role of the university in professional training. The text presents the first results of the research:The PUCs and the new guidelines for the journalism course: issues of ethics and citizenship for a sustainable world, and is based theoretically from academic texts on ethics and teaching journalism, and with the statements of Muniz Sodré, emeritus professor at UFRJ and Miguel Pereira, coordinator of the Projeto Comunicar/PUC-Rio. The study also brings together the main information obtained through dynamics carried out with groups of students of the ethics discipline of the journalism courses of the PUCs of Minas Gerais and Goiânia. With the method that unites the theory to the listening and application of the practice, the author sustains the need to invest in the academic formation of the journalist, with the rescue of ethics as a fundamental essence for journalism.

Keywords: Journalism. Teaching journalism. Ethic. Curricular guidelines. PUC.

\footnotetext{
1 Uma versão deste artigo foi apresentada no $15^{\circ}$ Encontro Nacional de Pesquisadores em Jornalismo, da Associação Brasileira de Pesquisadores em Jornalismo - SBPJor-, realizado em novembro de 2017, na ECA/USP, São Paulo.
} 


\section{Introdução}

Este artigo atenta para o fortalecimento da ética profissional como possível consequência da Resolução nº 1, de 27 de setembro de 2013, do Ministério da Educação (MEC), que institui as novas Diretrizes Curriculares Nacionais para o curso de graduação em Jornalismo e bacharelado. Acredita-se que durante as quase cinco décadas que o curso de jornalismo esteve acoplado ao curso de comunicação social como uma habilitação, a ética deixou de ser uma prioridade na formação jornalística.

O documento do MEC institui as Diretrizes Curriculares Nacionais para o curso de graduação em Jornalismo e bacharelado, a partir de regras e metas distribuídas em 18 artigos. As normas são fruto do trabalho da comissão de especialistas, nomeada pelo Ministério da Educação, por meio da Portaria No 203/2009, de 12 de fevereiro de 2009. Após três audiências públicas, ocorridas no Rio de Janeiro, Recife e São Paulo, abertas a todos os agentes de comunicação interessados em participar, foi produzido um relatório que faz uma análise do cenário atual do mercado de jornalismo e indica as necessidades curriculares para capacitação de um profissional "com formação universitária ao mesmo tempo generalista, humanista, crítica e reflexiva" (BRASIL, 2009, p. 16).

A análise apresentada neste texto tem como estudo de caso referencial os resultados preliminares da pesquisa: As PUCs e as novas diretrizes para o curso de jornalismo: questões de ética e cidadania por um mundo sustentável. Trata-se da minha tese de pós-doutorado, ainda em desenvolvimento, na Pontifícia Universidade Católica de Minas Gerais (PUC Minas), sob a coordenação do professor Mozahir Salomão Bruck. O estudo investiga como as sete pontifícias universidades católicas brasileiras, denominadas pontifícias por serem ligadas diretamente ao Vaticano e a Santa Fé, estão trabalhando para o cumprimento da Resolução do Ministério da Educação.

A pesquisa de pós-doutorado parte da premissa que a função social do jornalista está sendo deixada de lado não só no exercício da profissão como, também, na formação universitária. Acredita-se, em segundo lugar, que exista uma preocupação extrema das instituições de ensino superior em acompanhar o desenvolvimento técnico do mercado, o que promove, mesmo que involuntariamente, a diminuição da reflexão teórica substancial para a atuação do jornalista. Levando-se em conta este cenário hipotético no momento em que são 
implementadas as Diretrizes Curriculares Nacionais para o curso de graduação em Jornalismo e bacharelado, o objetivo principal do estudo é promover uma maior reflexão em torno da primeira das 16 questões elencadas no documento do MEC como considerações gerais:

[...] compreender e valorizar, como conquistas históricas da cidadania e indicadores de um estágio avançado de civilização, em processo constante de riscos e aperfeiçoamento: o regime democrático, o pluralismo de ideias e de opiniões, a cultura da paz, os direitos humanos, as liberdades públicas, a justiça social e o desenvolvimento sustentável. (BRASIL, 2013, p. 26).

Tem-se que as universidades católicas denominadas pontifícias devem contribuir para a reflexão mais profunda sobre temas caros para a formação do jornalista: ética e cidadania. Em especial, no momento em que se vivencia uma erupção permanente das ferramentas digitais de comunicação que promovem o fenômeno da "autocomunicação de massa" (CASTELLS, 2015, p. 22). Uma verdadeira polifonia de fontes e enunciados que enchem os indivíduos de informações pouco ou nada aprofundadas e pior, sem checagem prévia. Questões que serão tradadas como parte do objetivo mais amplo da pesquisa: contribuir para o debate do papel do cidadão na cobertura jornalística na era de uma "cultura da convergência", como alerta Jenkins (2009).

A pesquisa está sendo realizada em quatro etapas: revisão bibliográfica; levantamento de dados; entrevistas com coordenadores de cursos de jornalismo e/ou diretores de departamentos; e a realização de entrevistas com professores e alunos da disciplina de ética. Para o presente texto aplicou-se uma metodologia similar: leitura de textos acadêmicos sobre ética e ensino de jornalismo; realização de entrevistas com alunos e professores de ética dos cursos de jornalismo da PUC Minas e da PUC Goiás; e a coleta de depoimentos sobre ensino e ética dos doutores em comunicação Muniz Sodré, professor emérito da Universidade Federal do Rio de Janeiro (UFRJ) e Miguel Pereira, coordenador do Projeto Comunicar/PUC-Rio.

\section{Ética profissional}

A palavra "ética" vem do grego ethos que significa "modo de ser" ou "caráter". Já o termo cidadania vem do latim, civitas, que quer dizer "cidade" e significa o conjunto de direitos e deveres pelo qual o cidadão se relaciona com a sociedade em que vive. Em minhas pesquisas 
proponho a concepção de uma 'cidadania ética', a qual remonta a necessidade do resgate da função social do jornalismo como prioridade na profissão. Em outras palavras, proponho o fortalecimento do papel do profissional como cidadão diante dos acontecimentos.

Tal postura seria fruto de uma atuação virtuosa por hábito, uma ética centrada na justa medida como já defendia Aristóteles. "A virtude não é inata, mas resulta do hábito [...], ou seja, é necessário praticá-la, exercê-la efetivamente para nos tornarmos virtuosos." (MARCONDES, 2007, p. 40). Se os novos rumos do jornalismo apontam para a criação de novos modelos de negócios que primam pela reprodução quase automática da informação, ou seja, sem o rigor necessário com a verificação de fatos e dados, a essência ética do jornalista precisa voltar a ter o comando da seleção de notícias. É preciso impedir a consolidação do que o senso comum começa a chamar de pós-verdade.

Os primeiros textos sobre conceitos éticos recebem a assinatura do filósofo Platão (428348 a. C.) e reproduzem os diálogos, fictícios ou não, entre Sócrates (470-399 a. C.) e habitantes de Atenas, na Grécia. Aristóteles (384-322 a.C.), no entanto, foi o primeiro filósofo a usar o termo ética com um conjunto de normas e princípios que orientam a ação do homem. A ética aristotélica, como já foi dito, é centrada na justa medida.

\begin{abstract}
Devemos ser claros quanto ao fato de que toda conduta eticamente orientada pode ser guiada por uma de duas máximas fundamental e irreconciliavelmente diferentes: a conduta pode ser orientada para uma "ética das últimas finalidades", ou para uma "ética da responsabilidade". Isto não é dizer que uma ética das últimas finalidades seja idêntica à irresponsabilidade, ou que a ética de responsabilidade seja idêntica ao oportunismo sem princípios. (WEBER apud MARCONDES, 2007, p. 125).
\end{abstract}

A reflexão de Max Weber (1864 - 1920), como consta em Marcondes (2007), expõe um paralelo entre a ética da convicção e a da responsabilidade, esclarecendo que a segunda é mais crítica, valoriza as consequências dos atos e as relações existentes entre os meios e os fins das ações dos indivíduos e que, entretanto, não descarta a possibilidade de as duas éticas entrarem em conflito e uma delas prevalecer no ato de uma decisão. Weber me faz pensar no conceito de dialogismo elaborado por outro filósofo, Mikhail Bakhtin (1895-1975). Para este filósofo, a estética resulta deste acabamento que é dado a partir da relação com o outro, do diálogo; ele usa a estética literária para tratar de uma questão sobre a filosofia do ato: a relação de 
respondibilidade. A compreensão de que o ser, ao mesmo tempo que pratica uma ação, tem uma responsabilidade da ação, "A minha existência é única e eu não tenho álibi."2

A concepção de "respondibilidade" de Bakhtin permite pensar no papel do jornalista como agente social de transformação da sua própria sociedade. A escolha entre a sua convicção e a sua responsabilidade deve sempre contar com o olhar do outro, um cidadão como ele. Em síntese significa dizer que no ato da profissão ele deve agir como um cidadão que tem direitos a usufruir e deveres a cumprir. Ou, como bem analisou o professor Miguel Pereira, entender que:

Na verdade, a ética assume as configurações inerentes à sua ação prática. Significa dizer que a sua falta aparece mais explicitamente quando a ação humana se conduz de forma a não considerar o direito do outro e o direito coletivo. Não importa em que contexto essa ação acontece. Tanto pode ser um ato individual, como institucional, jurídico, educativo ou comunicacional. Em todos os setores da vida, a ética se faz presente, na medida em que trata do relacionamento entre pessoas em sociedade. (PEREIRA, 2002, p. 78).

Dito isto, para formar jornalistas éticos é necessário romper com análises que justificam qualquer atitude antiética como consequência automática do sistema capitalista que transformou o jornalismo em negócio, seus produtores em coempresários da notícia e a verdade em insumo quase desnecessário.

O clássico Procura-se ética para o jornalismo, do norte-americano H. Eugene Goodwin (1923-2012), lançado no início dos anos 1980, é considerado a primeira pesquisa séria a analisar os problemas éticos que cercam o jornalismo nos Estados Unidos. O então professor de ética da renomada Penn State University entrevistou 170 jornalistas ativos e entre tantas questões que cercam a ética destacou o conflito entre o jornalismo-profissão e o jornalismo-negócio.

Os jornalistas e o público precisam reconhecer que a natureza do negócio do jornalismo americano afeta sua ética. A necessidade da mídia ganhar audiências que possam ser vendidas para os anunciantes limita a liberdade dos editores em determinar seu conteúdo. [...] Portanto, as coisas que a mídia noticiosa tem que fazer para sobreviver como negócio vão afetar não apenas a sua tecnologia e seus procedimentos, mas também seus princípios éticos. (GOODWIN, 1987, p. 398).

\footnotetext{
${ }^{2}$ A frase foi dita por Ana Paulo Goulart, em sala de aula, em 2011, adaptando o pensamento de Mikhail Bakhtin sobre a sua filosofia do ato.
} 
Na imprensa brasileira, muitas vezes, a constatação de Goodwin serve como justificativa para atitudes antiéticas na prática jornalística. Isso, mesmo depois de importantes trabalhos como, por exemplo, o de Eugênio Bucci afirmar que "cada um, agindo eticamente constrói o próprio caráter em direção à virtude; no mesmo movimento, constrói o bem comum tal como ele é entendido em sua comunidade" (BUCCI, 2000, p. 16); e, ainda, nas salas de aula dos cursos de jornalismo se ouvir como um mantra a máxima de Abramo (1999, p. 109): “[...] minha ética como marceneiro é igual à minha ética como jornalista - não tenho duas".

A ética no jornalismo continua sendo tratada como algo abstrato, que estaria apenas na esfera da nossa subjetividade e não dos nossos atos objetivos. Em minhas entrevistas, com alunos da disciplina de ética no jornalismo, para uma pesquisa sobre as novas diretrizes curriculares para o curso de jornalismo, ouvi por diversas vezes que o mesmo professor que ensinava em sala a ser um profissional ético, cobrava nos trabalhos estratégias antiéticas como a falsa identidade para obter uma informação. Atitude que é crime, lembra Tófoli (2008), em sua reflexão sobre a prática jornalística à luz do Código de Ética Profissional, que acabava de ser atualizado:

O art. 307 do Código Penal Brasileiro prevê pena de detenção, de três meses a um ano, ou multa, se o fato não constitui elemento de crime mais grave, para quem usa o expediente da falsa identidade, ou seja, fazer-se passar, ou a terceiros, por outra pessoa existente ou imaginária. É o que diz a lei. (TÓFOLI, 2008, p. 68).

Outro aspecto que salta aos olhos quando pensamos na ética do dia-a-dia de uma redação contemporânea: a falta de atenção à qualidade do conteúdo noticioso. Um problema detectado por Carlos Alberto Di Franco, na década de 1990, quando a internet e seus derivados de mídia começavam a engatinhar no Brasil.

Criticamos uma troca de legendas, um empastelamento qualquer, um erro de diagramação. Mas não nos envergonhamos da informação incorreta, da matéria mal apurada, da manipulação informativa, do sensacionalismo brega, da notícia incompetente. Esquecemos que a qualidade é o outro nome da ética. Trabalhar pouco, trabalhar mal, trabalhar sem a técnica e a qualidade exigidas pela informação é um ataque aos princípios da ética. Os valores éticos não são um muro de arrimo para as legítimas aspirações de crescimento das empresas informativas. Ao contrário, são a mola propulsora das verdadeiras mudanças. (DI FRANCO, 1996 p. 166). 
O debate sobre a preocupação com qualidade como fator ético ganha novos ingredientes com a força das redes sociais no universo da comunicação e, ainda, com o fenômeno do jornalismo cidadão, chamado também de jornalismo democrático, jornalismo participativo ou jornalismo colaborativo. Um gênero jornalístico que tem, entre seus produtores, jornalistas não profissionais, cidadãos atentos a tudo e a todos que estão ao seu redor.

É nesta nova ambiência da mídia que as pessoas estabelecem seus valores, condutas e escolhas. Uma condição de vida que encontra na sociedade em rede, conforme Castells (2006), em que vivemos desde o fim do século XX, o espaço ideal para ser exercida. A sociedade em rede prima pela convergência de mídias em um espaço virtual onde muitas pessoas falam com milhares de outras. Ela fornece a todo e qualquer cidadão conectado à internet ferramentas que magnanimamente autorizam ao registro de fatos com valores-notícia, segundo Traquina (2002), até então exclusividade dos jornalistas profissionais.

Para agitar ainda mais o momento polifônico da comunicação soma-se o fenômeno da pós-verdade, um neologismo que enfraquece o valor dos fatos. Na política, a pós-verdade é emblemática quando um político fala inverdades para se eleger e, desta forma, seduz o eleitor que quer ouvir exatamente o que é dito. O leitor/ouvinte/espectador se fideliza ao veículo de comunicação com o qual ele concorda e só se informa por meio dele. O problema surge quando o jornalista embarca nessa fala inverídica, dá a ela destaque na veiculação e só depois vai averiguar sua veracidade ${ }^{3}$. Ou seja, primeiro a conquista da audiência, depois o primor pela apuração da verdade dos fatos.

\section{O ensino do jornalismo no Brasil}

As primeiras iniciativas para formação jornalística em curso superior foram registradas na Universidade de Breslau, na Alemanha, em 1806, e no Washington College, nos Estados Unidos, em 1869. De acordo com a análise de Melo (2009, p. 75), duas propostas distintas:

\footnotetext{
${ }^{3}$ Segundo o Dicionário Oxford, o termo pós-verdade é um "substantivo diz respeito a circunstâncias nas quais fatos objetivos têm menos importância do que crenças pessoais". A definição está na reportagem disponível em:< https://www.nexojornal.com.br/expresso/2016/11/16/O-que-\%C3\%A9-\%E2\%80\%98p\%C3\%B3sverdade $\%$ E2\% $80 \% 99$-a-palavra-do-ano-segundo-a-Universidade-de-Oxford>, que diz também que o termo está sendo usado para dizer que a verdade está perdendo o valor no terreno político. Acesso em: 3 mar. 2017.
} 
O curso europeu tinha perfil academicista, orientando-se no sentido de alavancar uma "ciência da imprensa". Por sua vez, o curso norte-americano era mais modesto, pretendendo simplesmente "aperfeiçoar tipógrafos", ou seja, ampliar seu conhecimento no âmbito das artes e ciências.

No Brasil, a implantação regular de um curso superior só foi possível no século seguinte, graças ao testamento deixado pelo paulista Cásper Líbero, diretor-proprietário do vespertino de sucesso dos anos 1940, A Gazeta.

Isto aconteceu em 1943, mas, devido aos entraves burocráticos e legislativos - pois o ensino de jornalismo, apesar de instituído por decreto em 1937, não fora regulamentado ainda pelo Ministério da Educação -, somente em 1947 a Faculdade abriria as portas para sua primeira turma, vinculada à Pontifícia Universidade Católica de São Paulo. (HIME, 2004, p. 1).

O curso da Cásper Líbero nasceu sob a influência das escolas europeia e norteamericana. Melo afirma que a formação universitária no Brasil vive uma oscilação entre os dois modelos: por um lado, visa a prática; mas por outro, também valoriza o pensamento acadêmico. De acordo com o pesquisador, as vertentes, academicista europeia e pragmática norteamericana, entretanto, acabaram sendo revistas na década de 1960, pela influência modernizadora do Centro Internacional de Estudos Superiores de Comunicação para América Latina (Ciespal).

O Ciespal, com sede da Universidade Central de Quito, no Equador, foi criado durante o período da Guerra Fria, pela Unesco, que demonstrava preocupação com a formação dos jornalistas "por acreditar que o jornalismo, enquanto uma instância da espera pública, tem a capacidade de agravar ou atenuar os conflitos sociais, partidários e internacionais" (AGUIAR, 2013, p. 164).

O Centro passou a pregar a modernização da educação universitária que, entre outros pontos, promovia a ruptura com a formação teórica, baseada no ensino clássico-humanístico, com destaque para os pensamentos éticos, jurídicos, filosóficos e literários. No Brasil, com o golpe militar de 1964, a receita do Centro chega às universidades brasileiras. Para o ensino do jornalismo, a proposta era clara: transformar os cursos de jornalismo em "institutos de comunicação". Para propagar seu projeto, o Ciespal realizou, em 1965, quatro seminários regionais na América Latina e no encontro do Rio de Janeiro introduziu no país a figura do profissional polivalente: o comunicador social. 
De fato, a figura do "jornalista polivalente- depois chamado de "comunicador socialfoi rejeitada pelas escolas do Brasil já no ano seguinte ao de sua invenção e esquecida nos currículos seguintes, que reafirmaram as tradicionais habilitações em jornalismo, publicidade, relações públicas, etc. Mas os cursos, contraditoriamente, passaram a se chamar "de comunicação social", adotando a linguagem padronizada pelo Ciespal para todo o continente. E a teoria estudada e desenvolvida nas escolas, longe de atender às necessidades de formação dos profissionais das diversas habilitações, continuou voltada às supostas necessidades de um comunicador alternativo que vive à margem da mídia e a despreza. (MEDITSCH, 1999).

Desde então, com o curso de jornalismo como habilitação, as escolas de comunicação, de uma forma geral, passaram por ajustes com o objetivo de se adequar às exigências tecnológicas impostas pelo mercado e acabaram por abrir mão da consistência na formação ética. O professor emérito da Universidade Federal do Rio de Janeiro, Muniz Sodré, não acredita que a separação do curso de jornalismo do curso de comunicação social seja a solução para o momento do jornalismo contemporâneo.

Eu acho uma grande besteira, porque pensa que o jornalismo constitui um saber a parte. Jornalismo constitui uma prática a parte, não um saber a parte. O jornalismo não tem nada a ver com a epistemologia. Jornalismo é uma prática de esclarecimento, de opinião, que, digamos, é um capítulo, um momento, um episódio dos estudos de comunicação. [...] A formação do jornalismo tem que sair desse discurso do deslumbramento, da celebração da técnica. Parece que é novidade o cara celebrar a técnica e tudo isso tem um campo de estudo enorme, mas esse campo de estudo é o da comunicação. O jornalismo é um episódio disso. Ele não é "transtemporal" no sentido que ele não possa morrer, mas a ideia do jornalismo ela continua viva, continua importante, só que ela é mais importante que o jornal. [...] essa cultura dos dados, do imediato, ela é rápida: uma hora é uma coisa e em pouco tempo some. O melhor desse campo da comunicação está nas universidades. Agora, a universidade ainda não conseguiu fazer uma ponte de enquadramento em alguma coisa que seja pública. Ela é muito isolada. (informação verbal). ${ }^{4}$

Já o professor Miguel Pereira, coordenador do Projeto Comunicar da PUC-Rio, apesar de considerar que o chapéu da comunicação social é muito amplo, ainda tem dúvidas quanto à eficiência das novas diretrizes curriculares do MEC.

\footnotetext{
${ }^{4}$ Entrevista concedida à autora, no dia 12 de julho de 2017.
} 
Fechar em uma especialidade corre o risco de ficar em cima dos interesses da classe. [...] O jornalismo se tornou institucional demais. Isso é ruim do jornalismo. Hoje, o jornalista faz a versão dele e não do interesse público. No jornalismo, seja ele qual for, quem está no jogo é o repórter. É ele quem decide. Ele não a visão de que aquilo esteja a serviço do público. A comunicação social foi um guarda-chuva durante a ditadura brasileira. A ditadura queria abarcar o jornalismo para ela. A ditadura queria descaracterizar o jornalismo enquanto tal, como crítico. $O$ jornalismo da época da ditatura era muito mais crítico do que o de hoje. Não eram todos os veículos, mas eu me lembro bem que o Roberto Marinho, por exemplo, dizia aos militares: vocês cuidem das questões de vocês que eu cuido dos meus comunistas. Na verdade, o jornalismo independe disso. Não é a ideologia que faz o bom jornalismo. O bom jornalismo é uma apuração bem-feita, um assunto de interesse coletivo, de interesse público. Isso que é um bom jornalismo. (...) Tem que voltar o curso de jornalismo para lá, para esse lugar da ética, da função social do jornalismo, e trabalhar cotidianamente nesse lugar e aprofundar isso. (informação verbal). ${ }^{5}$

O coordenador de graduação do Departamento de Comunicação Social da PUC-Rio, professor Leonel Aguiar, defende que a formação específica em jornalismo é essencial para garantir o direito do desenvolvimento de uma esfera pública democrática na sociedade brasileira contemporânea. A partir de reflexões feitas por autores como Traquina (2005), Gomes (2009) e Melo (2004), Aguiar tenciona o debate em torno da importância do jornalismo nas sociedades democráticas. Para o autor, valores éticos e normas deontológicas dão à profissão um espaço de destaque.

\begin{abstract}
Mais que elementos identitários que produzem os laços de interação de uma cultura profissional, esses valores também fundamentam a legitimidade social do jornalismo, conforme aponta Wilson Gomes, ainda que, na atualidade, só seja possível afirmar que o jornalismo vinculado ao princípio do serviço ao interesse público fique restrito aos temas políticos, a reponsabilidade ética não deve desaparecer. (AGUIAR, 2013, p. 166).
\end{abstract}

Aguiar (2013, p. 172) destaca que "a qualificação específica é um instrumento político de garantia do interesse público para informações de melhor qualidade jornalística, produzidas com responsabilidade social e parâmetros éticos". Acompanhando o pensamento de Aguiar, venho analisando os cursos de jornalismo das PUCs brasileiras e, neste artigo, apresento, a seguir, minhas primeiras reflexões.

\footnotetext{
${ }^{5}$ Entrevista concedida à autora, no dia 13 de julho de 2017.
} 


\section{As PUCs e o debate ético}

Apesar do senso comum compreender as PUCs como uma mesma administração e grade curricular, as sete Pontifícias Universidades Católicas existentes no país são totalmente independentes umas das outras e, consequentemente, seguem projetos pedagógicos distintos. Até o momento de produção deste artigo, a pesquisa de pós-doutorado, como já foi dito, estava em andamento e o trabalho de campo feito apenas na PUC Minas e na PUC Goiás. Nas duas universidades foram entrevistados os coordenadores do curso de jornalismo, os professores da disciplina de ética ministrada e aos alunos desta cadeira foi aplicada uma dinâmica e, em seguida, aqueles que quiseram participar do grupo focal conversaram comigo por cerca de 40 minutos.

Na PUC Minas, a disciplina Ética e crítica da mídia é obrigatória e oferecida no $7^{\circ}$ período do curso. Segundo o professor Enaldo Souza Ribeiro, o curso sempre foi ministrado a partir de episódios históricos, mas, os acontecimentos mundiais, no primeiro semestre de 2017, contribuíram para uma mudança no programa.

Coincidiu com a ideia da pós-verdade, que não é um conceito novo, é dos anos 90, mas o país vive falando da pós-verdade, a eleição do Trump. São coincidências históricas: o novo projeto do New York Times, do Washington Post. Isso despertou neles um interesse muito grande. Então, o modo que eu trabalho a matéria nesse período é totalmente diferente do modo que eu trabalhava no período anterior. Eu fazia a mesma coisa só que com fatos específicos: o mea-culpa do O Globo no Golpe Militar, por exemplo. Situações muito específicas e agora eu tenho uma situação mais global, que eu posso distribuir os conceitos da matéria (informação verbal) ${ }^{6}$.

Já na PUC Goiás, a ética é apresentada aos alunos com a disciplina Ética e jornalismo, oferecida no $4^{\circ}$ período aos alunos que só são autorizados a estagiar a partir do $6^{\circ}$ período. A carga horária semanal é de 1 h30min, por semana, e são duas turmas (diurno e noturno) de 29 alunos cada. O professor responsável pela disciplina, Osmar Magalhães, é filósofo por formação e objetiva despertar os alunos para a questão da ética, inclusive trabalhando a conjuntura política nacional, estadual e municipal.

\footnotetext{
${ }^{66}$ Entrevista concedia à autora, no dia 7 de abril de 2017.
} 
Os alunos são muito jovens e eu peço para eles verificarem as informações para ver se aquilo que está sendo noticiado hoje se mantém amanhã. Aqui no departamento nós temos deficiência de material para trabalhar, nós não temos, por exemplo, jornais em sala de aula. Por isso eu trago jornal, trabalho com alguns textos básicos e filmes como Sociedade dos poetas mortos para uma reflexão sobre o conceito de educação. Fiz um texto histórico da ética dos gregos até nós: a evolução dos conceitos de homem e mundo; as doutrinas éticas fundamentais de Sócrates e Aristóteles até chegar a Idade Contemporânea. [...]. Os alunos demonstram bastante interesse, mas estão preocupados com o mercado e eu digo a ele para não terem a ilusão com o mercado, com a formação técnica porque isso é insuficiente. Eu diria que a ética só vai se dar mesmo na prática, a universidade contribui muito pouco, talvez com alguns princípios fundamentais da ética, esse debate que se faz aqui, mas o embate que eles vão ter no trabalho é que vai consolidar essa visão. Uma disciplina que é dada uma vez por semana, que vale dois créditos, é muito pouco. Eram quatro créditos, mas enxugaram e a disciplina perdeu muito. A nossa área da filosofia só não perdeu o espaço total na universidade porque é uma universidade católica. (informação verbal) ${ }^{7}$.

A dinâmica proposta para os alunos das duas disciplinas foi a seguinte: os alunos receberam um papel em branco onde deveriam colocar o período que estão cursando, a idade e a informação se estavam fazendo estágio ou se já haviam estagiado. Em seguida ouviram as quatro situações descritas no Quadro 1 e para cada uma delas deveriam responder sim (S) ou não $(\mathrm{N})$.

\footnotetext{
${ }^{7}$ Entrevista concedida à autora no dia 22 de maio de 2017, na PUC Goiás.
} 
Quadro 1 - Descrição dos casos

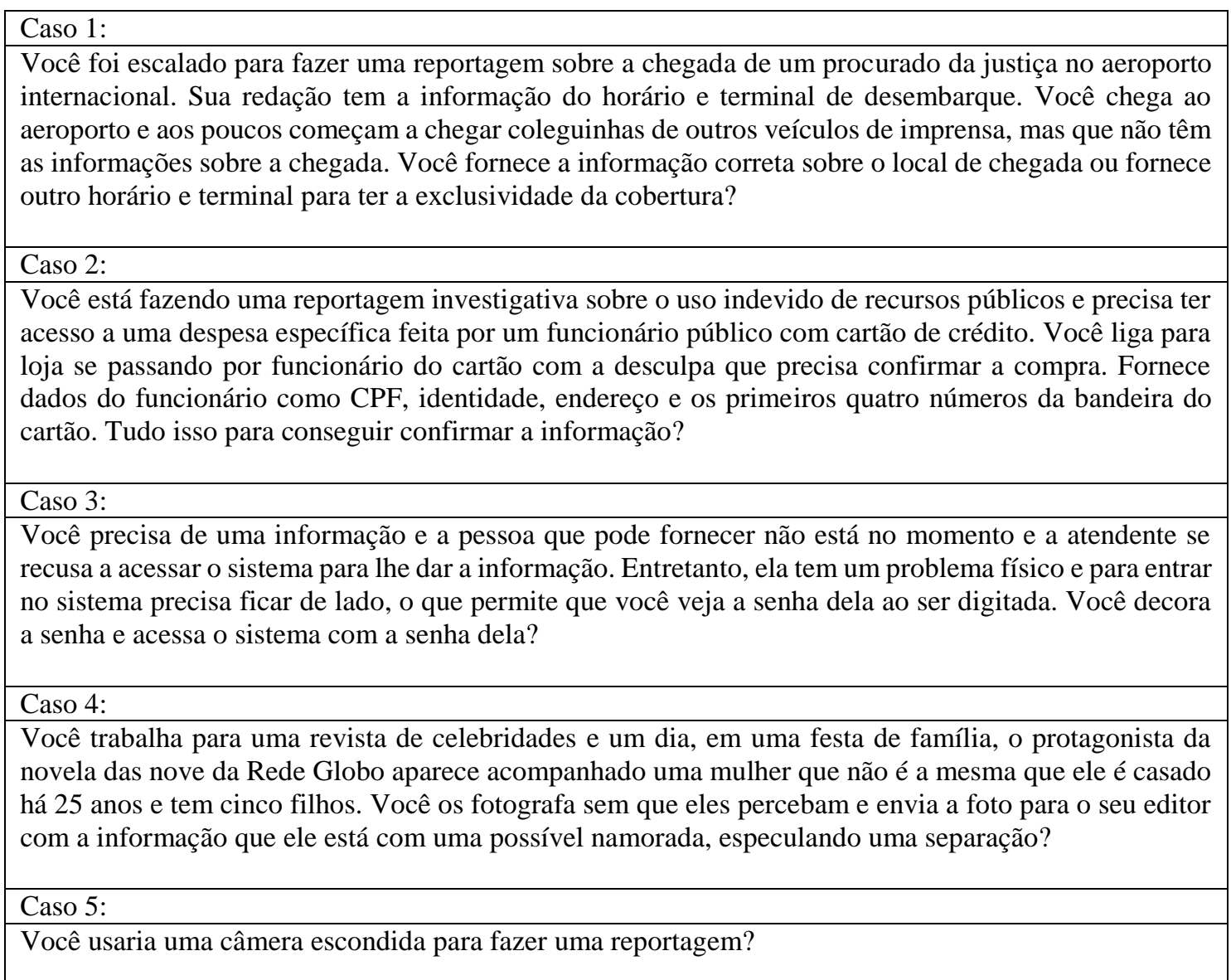

Fonte: Elaborado pela pesquisadora.

No dia 7 de abril de 2017, a dinâmica foi realizada com 25 alunos da disciplina Ética e crítica da mídia (Quadro 2). O resultado gera, no mínimo, alguma inquietação com relação à postura ética dos estudantes: 23 alunos disseram que não compartilhariam a informação correta com os colegas de outros veículos de comunicação; 14, passariam por outra pessoa para obter informações sobre compras feitas por um funcionário público com cartão de crédito; dois alunos decorariam a senha de uma funcionária para entrar no sistema de uma empresa e obter informações e um talvez fizesse isso; 15 alunos fotografariam um ator com sua acompanhante em uma festa e enviariam para o editor especulando uma separação do artista com a mulher com quem é casado há 25 anos; e, por fim, 24 estudantes usariam uma câmera escondida para fazer uma reportagem. 
Quadro 2 - PUC Minas

\begin{tabular}{|c|c|c|c|c|c|c|c|}
\hline Caso 1 & Caso 2 & Caso 3 & Caso 4 & Caso 5 & Idade & Período & Estágio \\
\hline $\mathrm{N}$ & $S$ & $\mathrm{~N}$ & $S$ & $S$ & 24 & $7^{\circ}$ & $S$ \\
\hline $\mathrm{N}$ & $\mathrm{S}$ & $\mathrm{N}$ & $\mathrm{N}$ & $S$ & 21 & $7^{\circ}$ & $\mathrm{N}$ \\
\hline $\mathrm{N}$ & $S$ & $S$ & $S$ & $S$ & & $7^{\circ}$ & $\mathrm{N}$ \\
\hline $\mathrm{N}$ & $S$ & $\mathrm{~N}$ & $S$ & $S$ & 20 & $7^{\circ}$ & $S$ \\
\hline $\mathrm{N}$ & $S$ & $\mathrm{~N}$ & $S$ & $S$ & 21 & $7^{\circ}$ & $S$ \\
\hline $\mathrm{N}$ & $\mathrm{N}$ & $\mathrm{N}$ & $\mathrm{S}$ & $\mathrm{S}$ & 21 & $7^{\circ}$ & $\mathrm{S}$ \\
\hline $\mathrm{N}$ & $\mathrm{N}$ & $\mathrm{N}$ & $S$ & $S$ & 21 & $7^{\circ}$ & $S$ \\
\hline $\mathrm{N}$ & $S$ & $\mathrm{~N}$ & $S$ & $S$ & 21 & $7^{\circ}$ & $S$ \\
\hline $\mathrm{N}$ & $\mathrm{N}$ & $\mathrm{N}$ & $S$ & $S$ & 21 & $7^{\circ}$ & $\mathrm{N}$ \\
\hline $\mathrm{N}$ & $\mathrm{S}$ & $\mathrm{N}$ & $\mathrm{S}$ & $S$ & & $7^{\circ}$ & $\mathrm{S}$ \\
\hline $\mathrm{N}$ & $\mathrm{N}$ & $\mathrm{N}$ & $\mathrm{N}$ & $\mathrm{S}$ & 21 & $7^{\circ}$ & $\mathrm{N}$ \\
\hline $\mathrm{N}$ & $\mathrm{N}$ & $\mathrm{N}$ & $\mathrm{N}$ & $S$ & 24 & $7^{\circ}$ & $S$ \\
\hline $\mathrm{N}$ & $S$ & $\mathrm{~N}$ & $\mathrm{~N}$ & $S$ & 20 & $7^{\circ}$ & $\mathrm{S}$ \\
\hline $\mathrm{N}$ & $S$ & $S$ & $S$ & $S$ & 22 & $7^{\circ}$ & $\mathrm{S}$ \\
\hline $\mathrm{N}$ & S & $\mathrm{N}$ & $\mathrm{S}$ & $\mathrm{S}$ & 25 & $7^{\circ}$ & $\mathrm{N}$ \\
\hline $\mathrm{N}$ & $\mathrm{N}$ & $\mathrm{N}$ & $\mathrm{S}$ & $S$ & 21 & $7^{\circ}$ & $S$ \\
\hline $\mathrm{N}$ & $\mathrm{N}$ & $\mathrm{N}$ & $\mathrm{S}$ & $S$ & 20 & $7^{\circ}$ & $\mathrm{S}$ \\
\hline $\mathrm{S}$ & $\mathrm{S}$ & Talvez & $\mathrm{S}$ & $\mathrm{S}$ & 21 & $7^{\circ}$ & $\mathrm{N}$ \\
\hline $\mathrm{N}$ & $S$ & $\mathrm{~N}$ & $S$ & $S$ & 23 & $7^{\circ}$ & $\mathrm{S}$ \\
\hline $\mathrm{N}$ & $\mathrm{S}$ & $\mathrm{N}$ & $\mathrm{N}$ & $\mathrm{S}$ & 23 & $7^{\circ}$ & $\mathrm{S}$ \\
\hline $\mathrm{N}$ & $S$ & $\mathrm{~N}$ & $\mathrm{~N}$ & $S$ & 23 & $7^{\circ}$ & $S$ \\
\hline $\mathrm{N}$ & $\mathrm{N}$ & $\mathrm{N}$ & $\mathrm{N}$ & $S$ & 20 & $7^{\circ}$ & $\mathrm{N}$ \\
\hline $\mathrm{N}$ & $\mathrm{N}$ & $\mathrm{N}$ & $\mathrm{N}$ & $S$ & 21 & $7^{\circ}$ & $S$ \\
\hline $\mathrm{N}$ & $\mathrm{N}$ & $\mathrm{N}$ & $\mathrm{N}$ & $\mathrm{N}$ & 20 & $7^{\circ}$ & $S$ \\
\hline $\mathrm{N}$ & $\mathrm{N}$ & $\mathrm{N}$ & $\mathrm{N}$ & $S$ & 35 & $8^{\circ}$ & $\mathrm{N}$ \\
\hline
\end{tabular}

Fonte: Elaborado pela pesquisadora.

Já os 14 alunos que participaram na dinâmica realizada na PUC Goiás, no dia 22 de maio de 2017, talvez por serem mais novos e ainda não terem vivenciado um estágio no mercado de trabalho, reagiram algumas vezes com indignação às situações apresentadas. Um resultado que registra, de certa maneira, uma oscilação dos estudantes na consolidação de uma postura ética: apenas um aluno não forneceria as informações corretas para os colegas de 
cobertura; oito forjariam sua identidade; três usariam a senha de outra pessoa indevidamente; seis fariam a foto do ator e repassariam para o editor; e 11 usariam uma câmera escondida para fazer uma reportagem. Os resultados constam no Quadro 3.

Quadro 3 - PUC Goiás

\begin{tabular}{|c|c|c|c|c|c|c|c|}
\hline Caso 1 & Caso 2 & Caso 3 & Caso 4 & Caso 5 & Idade & Período & Estágio \\
\hline $\mathrm{S}$ & $\mathrm{N}$ & $\mathrm{N}$ & $\mathrm{N}$ & $\mathrm{N}$ & 21 & $4^{\circ}$ & $\mathrm{N}$ \\
\hline $\mathrm{S}$ & $\mathrm{N}$ & $\mathrm{N}$ & $\mathrm{N}$ & $\mathrm{S}$ & 19 & & $\mathrm{~N}$ \\
\hline $\mathrm{S}$ & $\mathrm{S}$ & $\mathrm{N}$ & $\mathrm{N}$ & $\mathrm{S}$ & 19 & $4^{\circ}$ & $\mathrm{N}$ \\
\hline $\mathrm{S}$ & $\mathrm{S}$ & $\mathrm{S}$ & $\mathrm{N}$ & $\mathrm{S}$ & 19 & $4^{\circ}$ & $\mathrm{N}$ \\
\hline $\mathrm{S}$ & $\mathrm{S}$ & $\mathrm{S}$ & $\mathrm{S}$ & $\mathrm{S}$ & 19 & $4^{\circ}$ & $\mathrm{N}$ \\
\hline $\mathrm{S}$ & $\mathrm{S}$ & $\mathrm{S}$ & $\mathrm{N}$ & $\mathrm{S}$ & 20 & $6^{\circ}$ & $\mathrm{N}$ \\
\hline $\mathrm{S}$ & $\mathrm{S}$ & $\mathrm{N}$ & $\mathrm{N}$ & $\mathrm{S}$ & 22 & $4^{\circ}$ & $\mathrm{N}$ \\
\hline $\mathrm{S}$ & $\mathrm{S}$ & $\mathrm{N}$ & $\mathrm{S}$ & $\mathrm{N}$ & 18 & $3^{\circ}$ & $\mathrm{N}$ \\
\hline $\mathrm{S}$ & $\mathrm{S}$ & $\mathrm{N}$ & $\mathrm{S}$ & $\mathrm{S}$ & 20 & $4^{\circ}$ & $\mathrm{N}$ \\
\hline $\mathrm{N}$ & $\mathrm{N}$ & $\mathrm{N}$ & $\mathrm{N}$ & $\mathrm{S}$ & & & \\
\hline $\mathrm{S}$ & $\mathrm{N}$ & $\mathrm{N}$ & $\mathrm{S}$ & $\mathrm{S}$ & 19 & $3^{\circ}$ & $\mathrm{N}$ \\
\hline $\mathrm{S}$ & $\mathrm{N}$ & $\mathrm{N}$ & $\mathrm{S}$ & $\mathrm{S}$ & 18 & $3^{\circ}$ & $\mathrm{N}$ \\
\hline $\mathrm{S}$ & $\mathrm{N}$ & $\mathrm{N}$ & $\mathrm{S}$ & $\mathrm{N}$ & 19 & $3^{\circ}$ & $\mathrm{N}$ \\
\hline $\mathrm{S}$ & $\mathrm{S}$ & $\mathrm{N}$ & $\mathrm{N}$ & $\mathrm{S}$ & 21 & $3^{\circ}$ & $\mathrm{N}$ \\
\hline
\end{tabular}

Fonte: Elaborado pela pesquisadora.

Se analisarmos, caso a caso, pode-se afirmar que o período em que a disciplina é oferecida ao aluno é um fator que interfere na eficiência ou não do curso no que se refere ao ensino da ética. Enquanto os alunos que já estão no final do curso e já vivenciam como estagiários o dia-a-dia de uma empresa jornalística, na maioria das vezes, não hesitam em fazer de tudo para obter uma informação, os mais novos não têm a esperteza como prioridade.

Entretanto, mesmo entre os que estão às vésperas de se formar, há momentos de questionamento. "Eu fiquei em dúvida com o cartão de crédito, porque sendo um político fiquei 
na dúvida se ia fazer isso ou não. Eu não pensei no fato de estar cometendo um crime e sim que ele estava fazendo uma coisa ilegal" (informação verbal) ${ }^{8}$, comentou um aluno do curso de jornalismo da PUC Minas.

Alguns estudantes, também da PUC Minas, levantaram o dilema entre as decisões abarcarem tanto as esferas pessoal quanto profissional, outro estudante afirmou:

Eu fiquei na dúvida na festa de família, porque fiquei pensando no depois: como vai ficar a minha relação com os meus parentes? Mas na minha vida profissional eu teria sido bem-sucedida. Em quase todos os casos eu fiquei em dúvida pelo mesmo motivo", questionou uma aluna. "Eu tive dúvida na da senha, porque eu estaria me aproveitando de uma outra pessoa, e o pior, uma pessoa que tem uma deficiência." (informação verbal $)^{9}$.

\section{Considerações finais}

A pesquisa em andamento ainda tem muito material a ser analisado e, com certeza, poderá contribuir mais para o debate em torno do possível fortalecimento da ética profissional a partir das novas diretrizes curriculares do MEC para os cursos de jornalismo. O artigo apresenta suas primeiras reflexões, mas ajuda a consolidar um pensamento sobre a necessidade de investir na formação acadêmica do jornalista. Resgatar a ética como essência do jornalismo e a função social como prioridade da profissão é dever das universidades.

\footnotetext{
${ }^{8}$ Entrevista com alunos concedidas à autora, no dia 07 de maio de 2017.

${ }^{9}$ Entrevista com alunos concedidas à autora, no dia 07 de maio de 2017.
} 


\section{Referências}

AGUIAR, Leonel. As diretrizes curriculares e a formação específica em jornalismo. Alceu, Rio de Janeiro, v. 14, n. 27, jul. /dez. 2013.

ABRAMO, Claudio. A regra do jogo: o jornalismo e a ética do marceneiro. São Paulo: Companhia das Letras, 1999.

BRASIL. MINISTÉRIO DA EDUCAÇÃO. Conselho Nacional de Educação. Câmara de Educação Superior. Resolução no 1, de 27 de setembro de 2013. Diário Oficial da União, Brasília, seção 1, p. 26, 1 out. 2013. Disponível em: < http://portal.mec.gov.br/index.php?option=com_docman\&view=download\&alias=14242rces001-13\&category_slug=setembro-2013-pdf\&Itemid=30192 >. Acesso em: 10 maio 2016.

BRASIL. Ministério da Educação. Diretrizes curriculares Nacionais para o Curso de Jornalismo. Relatório da Comissão de Especialistas instituída pelo Ministério da Educação. Portaria n. 203/2009, 12 de fev. de 2009. Brasília, 2009. Disponível em: <http://portal.mec.gov.br/dmdocuments/documento_final_cursos_jornalismo.pdf.> Acesso em: 10 maio 2016.

BUCCI, Eugênio. Sobre ética e imprensa. São Paulo: Companhia das Letras, 2000.

CASTELLS, Manuel. A sociedade em rede. Rio de Janeiro: Paz \& Terra, 2006.

CASTELLS, Manuel. O poder da comunicação. São Paulo: Paz e Terra, 2015.

DI FRANCO, Carlos Alberto. Jornalismo, ética e qualidade. Petrópolis: Vozes, 1996.

GOMES, Wilson. Jornalismo, fatos e interesses. Ensaios de teoria do jornalismo. Florianópolis: Insular, 2009.

GOODWIN, H. Eugene. Procura-se ética no jornalismo. Rio de Janeiro: Nórdica, 1993.

HIME, Gisely Valentim Vaz Coelho. Na fundação da primeira escola de jornalismo do Brasil Cásper Líbero gera o conceito de jornalismo moderno. Revista Pj: Br - Jornalismo Brasileiro, São Paulo, n. 3, primeiro semestre 2004. Disponível em: <http://www2.eca.usp.br/pjbr/arquivos/artigos3_b.htm >. Acesso em: 27 jul. 2017.

JENKINS, Henry. Cultura da convergência. 2. ed. São Paulo: Aleph, 2009.

MARCONDES, Danilo. Textos básicos de ética: de Platão a Foucault. Rio de Janeiro: Zahar, 2007.

MEDITSCH, Eduardo. Crescer para os lados ou crescer para cima: o dilema histórico do campo acadêmico do jornalismo. Biblioteca Online de Ciências da Comunicação, Covilhã, 
1999. Disponível em: <http://www.bocc.ubi.pt/meditsch-eduardo-dilema-historicojornalismo.pdf $>$. Acesso em: 15 jul. 2017.

MELO, José Marques de. Os primórdios do ensino de jornalismo. Estudos em Jornalismo e Mídia, Florianópolis, v. 1, n. 2, p. 73-83, jul./dez. 2004.

MELO, José Marques de. Jornalismo: compreensão e reinvenção. São Paulo: Saraiva, 2009.

PEREIRA, Miguel. Jornalismo com Alma. In FERREIRA, Fernando (Org.). Ética na comunicação. Rio de Janeiro: Projeto Comunicar PUC-RJ, 2003, p. 75-81.

TÓFOLI, Luciene. Ética no jornalismo. Petrópolis: Vozes, 2008.

TRAQUINA, Nelson. O estudo do jornalismo no século XX. São Leopoldo: Unisinos, 2002.

TRAQUINA, Nelson. Teorias do jornalismo: porque as notícias são como são. Florianópolis: Insular, 2005. 